\title{
CORBIN, A. (2020): Terra Incognita. Une histoire de l’ignorance. París: Albin Michel
}

\section{Eguzki Urteaga*}

Alain Corbin acaba de publicar su última obra titulada Terra Incognita. Une histoire de l'ignorance en la editorial Albin Michel. En la introducción, el historiador galo observa que la identificación de la carencia, "el inventario y la medida de las ignorancias se imponen, como [elementos previos], a cualquier historiador que aspira a la comprensión de los [individuos] del pasado”, y, de esta forma, "de los desfases sociales del saber" (p. 9). De hecho, es imposible conocer las personas del pasado "sin discernir lo que no saben, bien porque todo el mundo lo ignoraba, bien porque no estaban en [condiciones] de saberlo" (p. 9). Para discernir los contornos de lo que no se sabe, es preciso "elegir un campo y sondear [sus] carencias" (p. 9). Con ese fin, el autor se centra en la Tierra, en la eliminación o el mantenimiento de sus misterios, así como "en la intensidad y el eventual desmoronamiento de las modalidades de terror o de asombro que suscitaba" (p. 9).

Esto implica interpretar la historia de las ciencias y de los descubrimientos en su relación con la pervivencia de ciertas ignorancias. Según Corbin, conviene distinguir, en los desfases sociales de la ignorancia, la configuración diversa de los misterios: por una parte, lo que solo podía ser soñado porque estaba inexplorado; por otra parte, lo que era observable pero era inexplicable; $\mathrm{y}$, por último, lo que correspondía a prácticas de exploración que hacían lentamente retroceder la ignorancia (p. 10). En ese sentido, la identificación de la carencia, que constituye el objeto de estudio de este libro, implica estar atentos, a la vez, "al ritmo de los descubrimientos y de la divulgación, es decir [a la repercusión] social de los hallazgos científicos a propósito de la Tierra (...); sin olvidar las representaciones de la figura de la Tierra, de la profundidad de su historia, de su geografía" (p. 11).

Profesor de Sociología en la Universidad del País Vasco (UPV-EHU) e Investigador asociado en el Social and Business Research Laboratory (SBRlab), centro de investigación de la Universidad Rovira i Virgilil. Doctor y Licenciado en Sociología por la Universidad Victor Segalen Buerdos 2 y Licenciado en Historia especialidad Geografía por la Universidad de Pau y de los Países del Adour. Autor de 34 libros et de más de 200 artículos cientificos. Presidente de Eusko Ikaskuntza Iparralde. Contacto: eguzki.urteaga@ehu.eus 
De hecho, durante todo el periodo estudiado, es decir desde el inicio del siglo XVIII hasta el final del siglo siguiente, prevalece el localismo, la demarcación del horizonte de la vida y de la mirada. "Esto es especialmente evidente en la historia de la percepción de los fenómenos meteorológicos" (p. 12). A lo largo de este trabajo consagrado a las ignorancias, transciende que estas no estaban siempre consideradas como un problema que fuese en contra de la felicidad del ser humano. En efecto, con el avance de la Ilustración, "la satisfacción progresiva de la libido sciendi tenía sus detractores" (p. 12). Encontramos esta tentación de la oscuridad en "varios viajeros cultos del Occidente romántico" (p. 13). Por lo cual, el estudio de la historia de las ignorancias y la realización de un inventario de las carencias que conciernen cada periodo de la historia moderna y contemporánea permite mejorar nuestro conocimiento de los individuos que las experimentaron (p. 16).

En la primera parte del libro, titulada "El escaso conocimiento de la Tierra en el siglo de la Ilustración", el autor recuerda que la catástrofe de Lisboa de 1755 fue precedida por el maremoto del 25 de noviembre de 1348 que devastó la baya de Nápoles si nos atenemos a la descripción realizada por Petrarca (p. 19). Un siglo más tarde, Bindo, embajador de Siena que residía en Nápoles, describió el terremoto padecido por esta ciudad el 4 de diciembre de 1456" (p. 20).

\section{Estas manifestaciones de una Tierra espeluznante se desarrollaban en un clima de miedo. [Las personas de aquella época veían en estos acontecimientos] la mano de Dios 0, secundariamente, la acción del [Demonio]. En trasfondo se situaban los episodios violentos revelados por la Biblia: el Diluvio (...), la destrucción de Sodoma y Gomorra, y, para terminar, el Apocalipsis. (p. 20)}

Frente a los desastres naturales, los individuos formados "por la escucha de los sermones y por numerosas prácticas culturales, pensaban que se trataba de plagas destinadas a castigar los pecadores. La preocupación por su propia salvación y la de la [comunidad] estaba en el origen de las reacciones psicológicas de las poblaciones. Dado que lo fundamental era [acceder al] paraíso, la obra divina parecía lógica" (p. 21). En esta óptica, "el desorden natural no era un reproche a Dios; [ya que la sensación del carácter justo] del castigo y la necesidad de preservación eran suficientes para evitar semejante reacción" (pp. 20-21).

Se produjo una lenta evolución entre el siglo XV, es decir el fin de la Edad Media, y 1755, fecha de la catástrofe de Lisboa (p. 21). A partir de entonces, la interpretación de estos acontecimientos conoció una inflexión. "El desastre, que seguía siendo [la] obra de Dios, no era percibido como [la] manifestación de su ira, y, por lo tanto, como [su] castigo, sino como el signo, obra de su misericordia, destinado a prevenir la damnación" (p. 21). Otro factor propiciaba la idea de neutralidad del castigo divino: la lenta toma en consideración de las causas secundarias (p. 21). Por lo cual, del siglo XVI al siglo XVII, es decir antes del desastre de Lisboa, "las representaciones del Diluvio [se hallaron] modificadas por una serie de interrogaciones" (p. 22). 
A partir de 1755, "la catástrofe [fue] un acontecimiento y no solamente un signo. Se [convirtió] progresivamente en un concepto que [permitió] pensar de otra forma el mundo y el [ser humano]. Fuera de cualquier referencia religiosa, [pudo] convertirse en objeto de análisis" (pp. 22-23). No en vano, "la idea de castigo divino, el temor de la damnación eterna y [el objetivo] primordial de la salvación no [desaparecieron] por ello del horizonte de las conciencias" (p. 23).

\section{En Lisboa, el 1 de noviembre de 1755, día de todos los Santos, a las 9h45 de la mañana, cuatro sacudidas se produje- ron en nueve minutos y el cielo se ensombreció de vapores sulfúricos. Algunos instantes más tarde, un maremoto (...) de una altura de cinco a seis metros devastó la ciudad. Hacia las 11h00, se produjo una sacudida. [Mientras tanto], un incendio se había iniciado que duró cinco o seis días. Los saqueos redoblaron el pánico. Los barrios más afectados fueron aquellos de la parte baja del centro urbano. (p. 23)}

Conviene recordar, a ese respecto, que, en aquella época, Lisboa era la tercera ciudad más importante de Europa y una de las metrópolis del catolicismo (pp. 23-24). Por lo tanto, la noticia del desastre se expandió por toda Europa. "El desastre fue a menudo descrito como una terrible catástrofe. La prensa subrayaba la magnitud de las destrucciones. (...) El derrumbe del comercio de una de las ciudades más activas de Europa fue particularmente [puesta de manifiesto]" (p. 24). En ese sentido, "la historia del terremoto concierne, a la vez, la sacudida y sus efectos, así como los mecanismos subterráneos que denominamos seísmo" (p. 25).

Es preciso recordar, a ese respecto, que las sociedades de esa época no comprendían "las causas de los terremotos. Eran frecuentes, dado que, entre 1600 y 1800, al menos 27 terremotos causaron daños considerables" (p. 25). "El desconocimiento de los mecanismos en esta materia era insoportable y las consecuencias desastrosas [eran] difícilmente controlables. (...) Además, el imaginario sísmico se centraba en las destrucciones urbanas" (p. 25).

$\mathrm{Si}$, hasta el siglo XVII, los numerosos terremotos acontecidos estaban casi ignorados y la información se circunscribía al ámbito local o regional, "durante la segunda mitad del siglo XVIII, en cambio, las sacudidas sísmicas acontecidas (...) fueron objeto de centenares de relatos, de debates (...) académicos, de decenas de artículos en los periódicos, de mapas, de catálogos" (p. 26). Si el interés creciente se produjo anteriormente al drama de Lisboa, este acontecimiento aceleró el movimiento (p. 26). De hecho, a partir de 1755, "la Academia de las ciencias [llevó a cabo] una verdadera política de estudio de los terremotos. Constituyó un conjunto de archivos sísmicos" (p. 26). En aquella época, "se multiplicaron los gabinetes de lectura, las clases públicas, las publicaciones científicas" (p. 26). El último cuarto de siglo coincidió especialmente con los grandes debates populares sobre la ciencia (p. 26).

Por lo cual, la catástrofe de Lisboa creó un espacio de discusión donde se oponían los científicos a propósito de sus orígenes. Se trataba de comprender la catástrofe, de interpretarla, de intentar protegerse de sus efectos, de medir sus relaciones con la actividad humana (pp. 27-28). 
A su vez, la focalización de la atención en los fósiles y los inicios del estudio de los estratos geológicos conducían, a la vez, "a cuestionar la unicidad y la universalidad del Diluvio y a modificar las representaciones de la edad de la Tierra" (p. 28).

\section{El terremoto de Lisboa y la serie de catástrofes [posteriores] han modificado la gama memorial de las consecuencias de los desastres. [A partir de entonces], la descripción de los estragos y su observación científica acompañaron el auge del sentimiento de piedad, de compasión hacia las víctimas. (p. 28)}

La catástrofe de Lisboa avivó el ansia de saber, representando un punto de inflexión en la historia de las representaciones de la Tierra para las personas que vivían en esa época (p. 29). Entre 1755 y las primeras décadas del siglo XIX, "una serie de interrogantes [surgieron] y numerosos temas [fueron] ásperamente debatidos, poniendo en evidencia las ignorancias, los [inicios] y la manera indecisa en la cual los [individuos de esa época] se representaban la Tierra y buscaban [esclarecer] los misterios" (p. 30). A ese respecto, conviene subrayar "la pobreza de las certezas [y] la importancia de las ignorancias compartidas" (p. 31).

Durante un largo periodo, "pensar que la Tierra tenía una larga historia (...) se enfrentaba al conjunto de la historia bíblica, la cual no [concernía] solamente el Diluvio sino el conjunto de las representaciones de [los tiempos]" (pp. 33-34). El imaginario de la larga duración de los tiempos geológicos, que se impuso a partir de la década de 1760-1770, fue "uno de los datos fundamentales de la representación de la historia de la Tierra y de su morfología" (p.35). En lo que alude al saber y a la ignorancia sobre la historia de la Tierra en vísperas del siglo XIX, prevaleció la indecisión y la tensión "entre visiones contradictorias en el seno de la élite [científica] europea" (p. 40).

En aquella época, "representarse el interior del globo [terráqueo], teniendo en cuenta la imposibilidad de la observación y de la realización de [sondeos en profundidad]", solo podía llevar a la ignorancia y a la elaboración de una serie de teorías sobre la Tierra (p. 43). Estas teorías estaban influidas por las ideas enunciadas por Platón en el Fedón (p. 43). A finales del siglo XVII, "triunfaban las teorías diluvialistas entre los que se interrogaban sobre la naturaleza del interior de la Tierra" (p. 44). Estas teorías fueron criticadas posteriormente y sustituidas por otras. De hecho, "la investigación a este propósito se [convirtió] en menos teórica [e] imaginativa" (p. 45). Por ejemplo, Kant consideraba que "ciertos fenómenos superficiales, tales como los terremotos, [permitirían] algún día hacerse una idea sobre la constitución interna de la Tierra” (p. 45). Bufón, de su parte, fundó su teoría sobre los conocimientos geológicos (p. 46).

Entre 1750 y 1830, lo esencial era vencer la ignorancia en la cual se encontraban a propósito de las rocas e "identificar las diferentes épocas que se [sucedieron] en la superficie del globo, gracias a la observación de la estratigrafía y de aquella de los fósiles minerales” (pp. 46-47). A partir de 1760-1770, se aceptó la idea de larga duración de los tiempos geológicos, lo que supuso el reconocimiento de la geología "como fuente histórica, gracias a la observación del apilamiento 
de los estratos" (p. 47). La geología se desarrolló con el afinamiento de las observaciones de superficie, "es decir el estudio de las morfologías superficiales y la recogida de indicios que podrían informarnos sobre la constitución y las condiciones de las profundidades" (p. 48). En lo que alude a las representaciones de la Tierra, desde finales del siglo XVIII hasta la primera mitad del siglo siguiente, el debate enfrentó los partidarios del neptunismo a aquellos del plutonismo (pp. 48-49).

A su vez, para comprender la historia larga de la ignorancia de los polos, conviene recordar el deseo profundo de conocerlos. Así, "durante la segunda mitad del siglo XVII, [se lanzaron] los primeros intentos de exploración” (p. 53). Si los científicos consideraban posible descubrir un paso por el noroeste, "los navegadores se preguntaban si era posible navegar sobre mares helados. Dibujaban un panorama trágico de esta navegación" (p. 54). A pesar de sus temores, "los intentos, que se multiplicaron, hicieron progresar la cartografía de las altas latitudes, aunque todos se saldaron por [sendos] fracasos" (p. 54). Como consecuencia de ello, la curiosidad se desplazó hacia otros objetos: "auroras boreales, cometas, manchas solares, figuras de la Tierra y grado de aplanamiento de los polos, viajes en el centro de la Tierra" (p.56). En suma, "la pobreza de las observaciones y, por lo tanto, de los conocimientos que conciernen los polos se hallaba compensada por el sueño y la utopía” (pp. 56-57).

Asimismo, durante el siglo XVIII, existía una ignorancia y una incomprensión total de los misterios de las profundidades marinas (p. 63). Es sabido que "el temor de lo ignorado es particularmente torturador. Estimula el sueño. De hecho, muy pronto, las [profundidades marinas fueron] dotadas de una increíble potencia emocional" (pp. 63-64). Estos lugares inaccesibles generaron, durante siglos, interrogaciones recurrentes e inspiraron ensoñaciones de tinieblas (p. 64).

A su vez, excepto las poblaciones de las cercanías de los masivos, los pastores, algunos vendedores ambulantes y ciertos militares, el conocimiento de la montaña en el siglo XVIII era limitado (p. 72). Para la mayoría de los habitantes de las llanuras, de las mesetas y de los litorales, la montaña era, a la vez, un territorio horrible y terrible, percibido ante todo como un obstáculo (p. 72). "Su inaccesibilidad, la violencia de sus tormentas y de sus vientos, sus tempestades de nieve; sin olvidar su población que [estaría] compuesta por hombres [salvajes y] feroces (...), la convertía en inhóspita" (p. 72). La alta montaña parecía estar abandonada por Dios y ocupada por el Demonio. "Sus nieves eternas parecían ser la señal de su maleficio" (p. 72).

No en vano, a finales del siglo XVII, la media montaña estuvo "de moda en el seno de las élites”, lo que contribuyó a modificar la mirada sobre la montaña (p. 73). En cuanto a la alta montaña, su conocimiento fue inicialmente iconográfico (p. 74). De la misma forma, la media montaña se benefició de las cualidades terapéuticas atribuidas a su aire (p. 75) y la alta montaña generó cierta fascinación que podía ser intensa (p. 76). En 1786 y 1787, se iniciaron las primeras experiencias ascensionales y la difusión de sus relatos. Como consecuencia de ello, "toda una [serie] de ignorancias que [concernían] la materia se [desvanecieron], mientras que se [amplió] el abanico social 
[del saber] que la [concernía]" (p. 77). A pesar de los avances realizados en el conocimiento de la montaña, seguía apareciendo a la mayoría de la población como "un horrible caos (...), un paisaje de ruinas. Continuaba apareciendo como convulsa, desregulada, autodestructiva; en una palabra, como un lugar de catástrofe" (p. 78). A ese propósito, "no olvidemos la avalancha, llevadera de la muerte blanca, terrorífica porque aparecía [como algo] imprevisible" (p. 79).

Hasta el siglo XIX, era necesario constatar la ignorancia vigente sobre los glaciares, "los mecanismos de su formación, de su deslizamiento, así como de su función" (p. 81). De hecho, la glaciología como ciencia solo apareció en 1892 (p. 81). Hasta entonces, "el deseo de saber (...) era extremadamente débil. Fue necesario esperar mediados del siglo XIX para que se busque verdaderamente comprender el flujo de un glaciar, la manera en que un cuerpo sólido [podía] deformarse, avanzar en los valles, etc.” (p. 81). Las poblaciones de aquella época temían el avance de los glaciares que amenazaban el futuro de los valles. "Ese aterrador diluvio de hielo corría el riesgo de engullirlo todo" (p. 82). Con el transcurso del tiempo, de suscitar el temor e incluso el horror, los glaciares pasaron a ejercer cierta fascinación. "Su belleza, su cambio de forma, su movimiento [maravillaban], al tiempo que [sorprendían]" (p. 83). "La observación demostraba que los glaciares se desplazaban, así como las grietas (...); que transportaban unos bloques de piedra; que erosionaban las rocas; que provenían de la cumbre de [las montañas]" (p. 83).

De su parte, a finales del siglo XVIII, "los volcanes [sustituyeron] los terremotos en el intento infructuoso de descubrir el interior de la Tierra. (...) Además, su valorización metafórica se intensificaba. Durante los años 1780, el volcán como tema filosófico estaba de moda. Constituía también una figura literaria muy [arraigada]" (p. 85). En lo que concierne los volcanes, la experiencia directa era limitada. Y, la pequeña minoría que tenía un conocimiento más profundo observaba que "los volcanes en actividad permanente emitían unos vapores acuosos, incandescentes [y], luego, (...) unos ríos de lava" (p. 86).

Conviene recordar que, a finales de la Edad Media y durante el Renacimiento, "el volcán había vuelto a ser objeto de comentarios literarios" (p. 87). Para los padres de la Iglesia católica, el volcán era percibido como un acceso al infierno, de modo que aterrorizaba a la población. "Sus erupciones, como otros fenómenos, manifestaban la ira de Dios, que [se expresaba a través de] las llamas" (p. 88). Posteriormente, el conocimiento de los volcanes fue propiciado por la extensión geográfica de la observación, especialmente realizada por Alexander von Humboldt (p. 90). Con el paso del siglo XVIII al siglo XIX, "el conocimiento de los volcanes resultaba también (...) de la moda y de la [intensa] representación pictórica y, simultáneamente, literaria" (p. 91). "La grandeza, la belleza del espectáculo de la erupción, especialmente su violencia nocturna, el temor que inspira, el infinito que sugiere, fascinaban entonces varios pintores, ingleses y franceses entre otros" (p. 91). 
Lo cierto es que el fenómeno volcánico seguía siendo ampliamente inexplicado y "la ignorancia de las causas (...) aumentaba el miedo" (p. 96).

A su vez, "tempestades, huracanes, ciclones, tifones, trombas, tornados, tormentas violentas, [nieblas cegadoras]: la lista es larga de fenómenos, cada vez mejor descritos, que [convertían] la Tierra en terrorífica. Eran las que suscitaban las fuertes inundaciones, provocaban los naufragios aterradores, los daños materiales más importantes. Participaban a la desgracia de los tiempos [pasados]" (p. 99). Por aquel entonces, la ignorancia era prácticamente total en lo que se refiere "a sus causas, su origen, su itinerario, su previsión. En esta segunda mitad del siglo XVIII, los eruditos sabían poco más que los individuos incultos” (p. 99).

En cambio, "la gran tempestad y todos los fenómenos que la componían [y] acompañaban, estaban muy bien documentados por los navegantes de todo tipo que, [por aquel] entonces, recorrían los mares, especialmente los más lejanos, viviendo constantemente en el temor de la ira de la atmósfera, que corría el riesgo de [provocar su naufragio] o de precipitarlos sobre los arrecifes" (pp. 99-100). La tempestad y el naufragio fueron unos temas primordiales "de la pintura y de la literatura del siglo de la Ilustración" (p. 100). "La ignorancia [y] la incomprensión avivaban la emoción, suscitaban ensueño, permitían sentir una [serie] de sentimientos que el saber había podido atenuar" (p. 101). Además, en materia de tempestades, "el localismo era preponderante" (p. 102).

Hubo que esperar el siglo XIX para que la ignorancia disminuya y se amplíe el saber, a pesar de la pobreza de los instrumentos de medida (p. 103). Si el termómetro estaba presente, no fue el caso ni del barómetro ni del pluviómetro (p. 103). Asimismo, se desconocía el lugar de origen de las formaciones atmosféricas, el itinerario de las tempestades, especialmente las que se producían en el mar (p. 107). Teniendo en cuenta la magnitud de las ignorancias, "la previsión y, secundariamente, los modos de preservación solo podían ser sumarios" (p. 107). Esto provocaba el mantenimiento de figuras tradicionales (p. 108). Así, "los ritos religiosos de protección de la tempestad, la tormenta, el granizo [se mantuvieron] hasta [mediados] del siglo XX" (p. 108). Pero, poco a poco, la ignorancia retrocedió gracias al auge de la meteorología que acabó formando parte de las ciencias oficiales (p. 109).

A su vez, a finales del siglo XVIII, el aire estaba de moda (p. 115). El problema era que, en 1780, "la práctica totalidad de los individuos ignoraba todo sobre las sensaciones y las emociones que podía procurar la mirada realizada desde el cielo. "En ese ámbito, la ignorancia era, no solamente total, sino que estaba universalmente compartida" (p. 115). En esta materia, la experiencia aérea en el interior de un globo aerostático fue una revolución. El giro se produjo en los años 1783 y 1784 (pp. 115-116). Tras el primer vuelo de los hermanos Mongolfier, las experiencias se multi- 
plicaron (p. 116). Todas estas hazañas, consideradas como heroicas, instituyeron "el vuelo aéreo, a la vez, como experiencia nueva, como serie de emociones desconocidas, (...) como instrumento científico y, sobre todo, como nuevo espectáculo colectivo" (p. 117).

Por último, analizar las maneras de concebir la Tierra durante la segunda mitad del siglo de la Ilustración implica "hacer el inventario de sus ignorancias y de sus creencias que [resultaron ser] erróneas" (p. 119). Si se sabía que la Tierra era un "planeta que giraba alrededor del Sol, tenía la forma de una esfera aplastada en los polos, (...) que su eje estaba inclinado en el plano del eclipse" y que tenía una larga historia, los polos seguían siendo inaccesibles, el interior de la Tierra era inalcanzable y lo mismo ocurría con las profundidades de los mares (pp. 119-120). A su vez, las nubes carecían de nombres, las tempestades eran observadas a nivel local, su itinerario era imprevisible y su origen seguía siendo desconocido (p. 120). De la misma forma, "ni los volcanes ni los terremotos eran explicables" (p. 120). Y, "los glaciares mantenían todo su misterio" (p. 120). Simultáneamente, la élite científica era reducida y sus escritos solo eran accesibles a una pequeña minoría (p. 120).

En la segunda parte del libro, titulada "El lento retroceso de la ignorancia (1800-1850)", Alain Corbin observa que, "del inicio del siglo XIX a los (...) años 1860, que [constituyeron] un giro fundamental en la historia de Occidente, la ignorancia, ciertamente, disminuyó en ese ámbito, pero en una escasa medida" (p. 125). En numerosos ámbitos, la ignorancia de la Tierra siguió siendo completa (p. 126). No en vano, entre 1820 y 1840, se produjo un retroceso de la ignorancia que provocó una transformación de la visión de la temporalidad de la superficie de la Tierra (p. 127). A partir de entonces, pudieron explicarse el origen y la evolución de los glaciares y numerosas preguntas encontraron respuestas, aunque fuesen parciales y momentáneas (p. 130).

Así, el retroceso de la ignorancia concernió todo lo que aludía a la historia, la estructura y la morfología de la Tierra (p. 131). Tres datos fundamentales modificaron la lectura geológica de la Tierra. El primero concernía la disputa entre el catastrofismo y el continuismo. El segundo aludía a la emergencia de la estratigrafía paleontológica. El tercero se refería al debate proveniente del calor íntimo del globo y, sobre todo, del espesor de la corteza terrestre (p. 131). Estos datos condujeron a renovar su mirada sobre la Tierra, "una nueva mirada informada por la percepción (...) de formas geológicas" (p. 132). En suma, "a lo largo de la primera mitad del siglo XIX, la lectura de la Tierra, de los periodos de su historia, de sus movimientos superficiales, [se afinaron]" (p. 137). Pero, la difusión de estos conocimientos en la población fue limitada por la pobreza de la divulgación de estos ámbitos (p. 137).

De finales del año 1815 a inicios de junio de 1818, la Tierra parecía a los habitantes de Europa central y occidental, así como a los de Estados Unidos, [más terrorífica que nunca]; y el terror se hallaba amplificado por la total ignorancia ante las causas del desorden intenso del cielo y de la Tierra. (p. 139). 
Abundaban los testimonios de fenómenos terroríficos observados y analizados por grandes científicos (p. 139). Varias cosechas "fueron destruidas y la última gran hambruna [identificada] en los países de Occidente causó millones de muertos. Las epidemias que siguieron, especialmente la del tifus, añadieron al desastre" (p. 140). "La creencia en la proximidad del fin del mundo y del Juicio Final se expandió" (p. 140). Si esta visión parece excesiva, no lo es "la influencia de esta crisis sobre los artistas de la época” (pp. 141-142). No en vano, los fenómenos volcánicos seguían siendo ampliamente inexplicados, a pesar de la fascinación que ejercían sobre la población (p. 142).

De la misma forma, "los individuos que vivían en 1850, no sabían más sobre las profundidades marinas que sus predecesores del extremo fin del siglo XVIII. Los mitos, las leyendas, los ensueños de [las] profundidades (...) seguían anclados en las memorias y los imaginarios” (p. 147). Y, los avances científicos fueron mínimos entre 1830 y 1850 (p. 148).

En vísperas del siglo XIX, en poco tiempo, la comprensión de la textura de las nubes, de los procesos de su formación, el aprendizaje de la nomenclatura inamovible de las formas y los mecanismos de las precipitaciones [hicieron] retroceder la ignorancia, al tiempo que unos pioneros, [gracias a unos vuelos] en los [globos aerostáticos, generaron] un nuevo conocimiento del espacio aéreo" (p. 153). Luke Howard contribuyó a esta transformación (p. 153). Su aportación concernía, a la vez, "los mecanismos de formación de las nubes y su duración. Sobre todo, proponía una nomenclatura de sus formas. (...) La nomenclatura de Luke Howard distribuía las nubes según tres formas básicas, completadas por otras" (p.154). Esta nomenclatura "se fundaba en la altitud, la temperatura del aire y (...) la radicación del suelo" (p. 155). Esta nueva manera de comprender el mundo aéreo "facilitó la entrada de la meteorología en el ámbito público" (p. 155). El retroceso repentino de la ignorancia interesó e incluso apasionó a ciertos pintores y artistas (p. 156). Fue el caso de Chateaubriand y Goethe (p. 156).

Para terminar, entre finales del siglo XVIII y 1859, "la ignorancia sobre todo lo que concernía los polos no [retrocedió], a pesar de un gran número de expediciones, la mayoría infructuosas, y del interés prestado por la población a unas regiones míticas" (p. 165). Esto estimulaba el imaginario de los escritores y pintores de la época (p. 165).

En la tercera parte del libro, titulada "La Tierra y el retroceso de la ignorancia (1860-1900)", el historiador galo constata que las profundidades marinas, que eran completamente opacas en 1850, perdieron parte de su misterio a finales del siglo XIX. "[Empezaron] a ser visitadas con la [instalación] de los cables transatlánticos. Para ello, [fue] necesario imaginar y realizar máquinas para sondear y dragar, fabricar interminables cabestrantes y sus bobinas. (...) La proliferación de los cables, iniciada en los años 1860, no cesó hasta finales del siglo" (p. 175). Este esfuerzo estaba vinculado a la electrificación (p. 175). Para ello, se procedió a la medida de las grandes profundidades (p. 177). A su vez, se midieron las corrientes y se conoció la fauna de las profundidades 
marinas compuesta por especies desconocidas hasta la fecha (p. 178). Además, "la ciencia de las [profundidades marinas] ofrecía una nueva explicación de los terremotos y de los maremotos. Estos aparecían, a partir de entonces, como los efectos de los derrumbes periódicos de los grandes fondos" (p. 180).

A su vez, "la ignorancia concerniente la atmósfera [retrocedió] mucho durante la segunda mitad del siglo XIX" (p. 183). En ese ámbito, el avance fue "suscitado por el deseo de mejorar la circulación marítima anticipando el acontecimiento de tempestades, especialmente a lo largo de las costas" (p. 184). Así, una red meteorólogo-telegráfica fue creada, hecha de diversos componentes (p. 185). Se trataba de cartografiar el cielo antes de realizar previsiones. "Para hacer [previsiones efectivas], era preciso construir una ciencia del movimiento de masas de aire, identificar y cartografiar las ondas atmosféricas" (p. 156). Si, a partir de los años 1860, "los conceptos de masas de aire y de circulación atmosférica eran de uso corriente en meteorología", el principal problema consistía en "medir la difusión de tales conocimientos en el seno del cuerpo social" (p. 187).

Y, durante la segunda mitad del siglo XIX, y particularmente a finales de la década de 18601870, los viajes aéreos continuaban [fascinando], especialmente en Francia" (p. 191). El placer de contemplar la superficie terrestre dejó lugar a la finalidad científica. "Estudiar la atmosfera, su extensión y su espesor constituía (...) lo esencial. (...) El objetivo era explorar desde arriba la superficie terrestre, su morfología, su vegetación", etc. (p. 192). Pero, lejos de hacer retroceder la ignorancia, "el viaje aéreo participaba a la industria del espectáculo urbano" (p.192). De hecho, hubo que esperar treinta años para que se pongan en evidencia "las capas superiores de la atmósfera o, más exactamente, de la muy alta atmósfera” (p. 193).

Durante este mismo periodo, "el volcán continuó fascinando más que cualquier otra montaña. (...) Esta fascinación [nació] de los relatos de catástrofes y del espectáculo de las erupciones que [presentaban] el volcán como el lugar más peligroso de la Tierra" (p. 195). En materia de volcanes, la ignorancia retrocedió gracias a "la ampliación considerable de la geografía de los volcanes" (p. 196). A su vez, el conocimiento y la comprensión de los mecanismos volcánicos mejoraron. Así, los científicos consideraban que "las materias volcánicas surgían de las profundidades de la Tierra" (p. 199).

Asimismo, "la parte esencial del retroceso de la ignorancia sobre los mecanismos de la glaciación data de la primera mitad del siglo XIX” (p. 203). Los avances concernían las previsiones sobre las edades glaciares. Contribuyeron "a educar la mirada sobre numerosas regiones. En primer lugar, nuevas investigaciones [revelaron] las variaciones periódicas de los glaciares y la extensión geográfica de las antiguas glaciaciones" (p. 204). Los estudios llevados a cabo durante este medio siglo mostraron "la extensión hasta entonces insospechada de las antiguas glaciaciones" ( $p$. 
204). Esto dio lugar a la introducción, hacia 1900, en Suiza y luego en Francia, "de una nueva disciplina, la glaciología” (p. 205). Además, los principales descubrimientos fueron ampliamente divulgados ( $\mathrm{p} .205)$.

En cambio, se mantuvo cierta ignorancia a propósito de los ríos, "percibidos esencialmente como unas fronteras políticas más o menos fáciles de superar, como unos ejes de navegación y como causas de terribles inundaciones" (p. 207).

Durante la segunda mitad del siglo XIX, (...) la geología, el nacimiento y la fecundidad de la hidrología, [y], posteriormente, al extremo fin del periodo, la espeleología [hicieron retroceder] la ignorancia [sobre] todo lo que concernía los ríos. (p. 207).

En esa época, mientras que los geólogos abordaban el fluvialismo y mostraban la importancia de los ríos, "ciertos viajeros [estaban] fascinados por los cauces, las orillas, las desembocaduras de los ríos" (pp. 207-208). Victor Hugo fue uno de ellos (p. 208). "La literatura fluvial, destinada entonces a un amplio público, se [enfrentaba] a la literatura policiaca” (p. 211).

Después de siglos durante los cuales las inundaciones inspiraron el terror, la aparición y el posterior desarrollo de la hidrología quiso comprender los mecanismos de las inundaciones ( $p$. 212). En Francia, "ese deseo [fue] avivado por la voluntad de Napoleón III, [directamente concernido] por la grande inundación de 1856, que [afectó a la mayor] parte de Francia y [con] la cual el emperador se había personalmente comprometido" (p. 212). Así, en 1872, emergió, de manera científica, la hidrografía fluvial (pp. 212-213). En 1878, "la mayoría de los departamentos [galos] estaban dotados de servicios, a la vez, meteorológicos e hidrográficos” (p. 213). El estudio hidrográfico implicaba “conocer la fuente, la extensión (...), el caudal, el régimen, los afluentes, la embocadura y la historia de las [inundaciones] cada año" (p. 213). La hidrología parecía poder aportar unas respuestas a las preguntas relativas a "las cuevas, los precipicios donde las aguas se [engullían], su circulación subterránea y su resurgimiento, las cuevas [por las cuales transitaban]" (p. 213). Existía una curiosidad por los orígenes de los ríos, especialmente del Nilo y del Misisipi (p. 215).

Lo cierto es que la mirada sobre la Tierra, a lo largo de la segunda mitad del siglo XIX, se benefició de los descubrimientos de la geología y de la geografía física (p. 217). "Los geólogos de esa época [hicieron] progresar [considerablemente] la comprensión de la formación de las montañas, en primer lugar, gracias a unos modos de observación más rigurosos (...). Esto permitía distinguir claramente las capas estratificadas, invertidas, arrugadas, a veces volcadas sobre sí mismas, a veces cortadas en retazos. Los geólogos (...) identificaban con precisión, las fallas, las fracturas y toda [una] serie de manifestaciones de dislocación de la corteza terrestre" (p. 218). En aquellos tiempos, la geografía física tenía grandes pretensiones, ya que tenía la ambición de "englobar la aerografía, la hidrografía, pero también la geognosia y la descripción de todas las formas telúricas de la superficie” (p. 220). 
Asimismo, "la imposible accesibilidad de los polos, a pesar de las expediciones llevadas a cabo desde hace varios siglos, [dejó] la vía libre a la imaginación, estimulada por el fracaso. La pasión de la opinión [pública], la inmensidad de la literatura policiaca [resultaban] del fracaso y de la ignorancia mantenida" (p. 228). En la opinión pública, "los terrores científicos [sustituían] aquellos inspirados por el Diluvio bíblico" (p. 230). La fascinante idea "de un mar libre de hielo en el polo constituyó un dato del imaginario importante" (p. 230). No en vano, "a lo largo de los años 1870, se abandonó poco a poco la idea de partir a la búsqueda del mar libre” (p. 233). Pero, el imaginario concerniente los polos "continuaba mezclando el relato de las hazañas heroicas, en barco o en trineo, el gusto por la aventura y la atracción por el descubrimiento científico” (p.233). Además de las revistas de divulgación científica, un gran número de relatos y de novelas trataron de los polos (p. 234). Sus autores apasionaron a los lectores (p. 235).

Los años 1850-1900 corresponden, en Francia especialmente, "a la Edad de Oro de la divulgación" (p. 237). Cuatro vectores fueron priorizados: la prensa, las bibliotecas, las conferencias y las exposiciones.

- "El medio más eficaz de la divulgación del conocimiento científico durante las últimas décadas del siglo XIX [fue] la lectura de revistas” (p. 238). Existieron unas cincuenta revistas científicas generalistas destinadas a un amplio público (p. 238). A nivel mundial, se pasó de 750 revistas en 1800 a 80.000 publicaciones en 1895 (p. 239). Muchas de ellas dedicaban sus páginas a los relatos de exploraciones y aventuras (p. 239).

- Las bibliotecas populares y escolares conocieron un auge considerable (p. 245).

- Las conferencias desempeñaron un rol importante hasta mediados del siglo XX (p. 246).

- Las exposiciones, especialmente universales, jugaron un papel no desdeñable (p. 251).

En definitiva, en vísperas del siglo XX, "la ignorancia de la Tierra subsistía en numerosos ámbitos, pero había retrocedido, desde 1860, mucho más rápidamente que durante el siglo precedente" (p. 255). De hecho, en 1900, se seguía sin conocer los polos. En esa fase, se había ciertamente dibujado la geografía de las profundidades marinas, [se habían realizado] unos mapas, [se había extraído] una fauna y una flora de las [profundidades marinas]" (p. 255). A su vez, "las profundidades telúricas seguían siendo desconocidas" (p. 255). No en vano, la ignorancia, anteriormente total, de la Tierra había retrocedido, relativamente claramente, durante los últimos cuarenta años" (p. 256). Así, se atribuía una edad a la Tierra y el conocimiento de los glaciares había mejorado. "Se empezaba a comprender la manera en que se efectuaba la circulación subterránea de las aguas y se había [identificado el origen] de todos los grandes ríos" (p. 256). Asimismo, "los datos que [marcaron] el retroceso de las ignorancias [fueron] divulgados con más intensidad que precedentemente" (p. 257). No obstante, esta divulgación del conocimiento era limitada y se dirigía a un público restringido (p. 258). 
Hoy en día, en cambio, la ignorancia ha reculado considerablemente. El conocimiento creado por los avances de la informática, las nanotecnologías, la inteligencia artificial, sin hablar de la robótica, es considerable. Asimismo, "la arqueología por satélite [modifica en profundidad] el conocimiento del pasado" (p. 259). Lo cierto es que "conocer [y] comprender los [seres humanos] de tiempos antiguos supone tener en cuenta lo que no sabían. Semejante perspectiva aclara sus decisiones y sus marcos de pensamiento. Es la razón por la cual, [el autor ha] concebido este libro como un alegato a favor de una historia de la ignorancia" (p. 260).

Al término de la lectura de esta obra magistral de Alain Corbin, es indispensable reconocer la originalidad del objeto de estudio y de la perspectiva elegidos por el autor en su afán de proponer una historia contemporánea de las sensibilidades. Gracias a una amplia cultura literaria y científica, y centrándose sobre todo en los siglos XVIII y XIX, nos ofrece una historia de las ignorancias sobre la Tierra. Lo hace elaborando una obra, a la vez, bien documentada y escrita en un estilo literario que compagina precisión y riqueza del lenguaje. No en vano, de cara a matizar la valoración sumamente positiva que merece este libro, se echa en falta una prolongación del análisis durante el siglo XX que representa un periodo sinónimo de salto cuantitativo y cualitativo del conocimiento sobre la Tierra en sus diferentes componentes. Asimismo, la sucesión de capítulos sobre los polos, los volcanes, el aire o las profundidades marinas en cada una de las tres partes que constituyen esta obra genera una sensación de redundancia.

En cualquier caso, más allá de estas reservas, la lectura de esta obra resulta indispensable para mejorar nuestro conocimiento de la ignorancia sobre la Tierra durante los siglos XVIII y XIX, y como ilustración de la historia del conocimiento y de las sensibilidades. 